\title{
Greetings from Academician B. Enkhtuvshin, President of Mongolian Academy of Sciences
}

$\mathrm{W}$ e, Mongolian scientists, are highly appreciative of the $7^{\text {th }}$ Ministerial Conference of the Community of Democracies taking place in the capital city of our country with a great heritage of ancient culture and history, and send warmest greetings to the participants of the Conference.

Our researchers and scientists view that Mongolia has accomplished the twofold objectives of transition to market economy and political democracy.

Nevertheless, we believe that the study of the market economy formation and pressing issues of the Mongolian development still remains to be an important responsibility and therefore, have been implementing joint research projects and programs with the participation of international and national scientists in these areas.

For instance, our scientists, with the support of the UN Democracy Foundation and UNDP have implemented a project "Support in achieving MDG-9 on Human Rights and Democratic Governance" in 2007-2011. We also, having studied the state of democracy after the Fifth International Conference of New or Restored Democracies (ICRND-5) identified performance indicators of the Mongolian democracy.

I would like to congratulate the Institute of International Studies of our Academy and the editorial board of the annual journal "Mongolian Journal of International Affairs" for devoting the journal's 2013 edition to this important event - the $7^{\text {th }}$ Ministerial Conference of the Community of Democracies. This is the gift of our academic community to you and another contribution to the development of democracy education.

I take this very pleasant opportunity to express our warmest best wishes for success in the deliberations of the conference whereby greatly contributing to the further advancement of democratic process in the world.

Welcome to Mongolia, the Land of Eternal Blue Sky. 